Rabaska

Revue d'ethnologie de l'Amérique française

\title{
Arsenault, Georges. La Chandeleur en Acadie. Tracadie-Sheila (Nouveau-Brunswick), Éditions La Grande Marée, 2011, 142 p. ISBN 978-2-349-72275-1
}

\section{Bertrand Bergeron}

\section{Volume 10, 2012}

URI : https://id.erudit.org/iderudit/1013556ar

DOI : https://doi.org/10.7202/1013556ar

Aller au sommaire du numéro

Éditeur(s)

Société québécoise d'ethnologie

ISSN

1703-7433 (imprimé)

1916-7350 (numérique)

Découvrir la revue

Citer ce compte rendu

Bergeron, B. (2012). Compte rendu de [Arsenault, Georges. La Chandeleur en Acadie. Tracadie-Sheila (Nouveau-Brunswick), Éditions La Grande Marée, 2011, 142 p. ISBN 978-2-349-72275-1]. Rabaska, 10, 233-235.

https://doi.org/10.7202/1013556ar d'utilisation que vous pouvez consulter en ligne.

https://apropos.erudit.org/fr/usagers/politique-dutilisation/ 
Le moins qu'on puisse dire, c'est que Achard sait raconter une histoire et capter l'intérêt de ses lectrices et lecteurs du début à la fin. Sa plume est juste, alerte, châtiée évidemment. Il sait manier l'ironie et la dérision, voire tâter de l'humour à l'occasion. Il est toutefois un reproche important à adresser au compilateur, Victor-Lévy Beaulieu qui, dans la bibliographie finale, a omis de préciser la référence exacte de chacun des textes retenus. Le lecteur reste donc sur son appétit, ne sachant jamais à quel recueil chaque texte est rattaché. Pour le chercheur que je suis, voilà une lacune importante.

AuréLIen BoIvin Université Laval, Québec

Arsenault, Georges. La Chandeleur en Acadie. Tracadie-Sheila (NouveauBrunswick), Éditions La Grande Marée, 2011, 142 p. ISBN 978-2-34972275-1.

La Chandeleur en Acadie est à ranger parmi les monographies. Nonobstant sa division en dix chapitres précédés d'un " Avant-propos » et des « Remerciements » d'usage, et suivis d'un « Glossaire », on peut l'aborder selon deux axes qui renvoient à une même préoccupation qui traverse le temps long des Fêtes : manger, s'empiffrer. D'où vient cette obsession?

Ce comportement peut paraitre trivial pour un esprit superficiel, mais il prend tout son sens lorsqu'il s'inscrit au cœur d'une civilisation agraire entièrement soumise aux caprices du temps. Les sociétés agricoles sont des sociétés de pénurie ponctuée par quelques périodes d'abondance surtout lors des récoltes. La gestion et la conservation des aliments deviennent une préoccupation quotidienne principalement en période hivernale. La pénurie intégrée à l'économie domestique est rompue à des moments privilégiés pour céder la place à de brefs excès de bombance pour des raisons qui tiennent à la fois de la psychologie et de la magie. Il est vital de relâcher la tension alimentaire pour ne pas sombrer dans la déprime en s'adonnant à la surconsommation périodique qui fait oublier un instant le joug de la privation. La bombance agit comme un élément provocateur destiné à défier la nature par un excès de consumérisme afin de la forcer à rendre la pareille en produisant au centuple lors des moissons. Ce défi peut s'exprimer de cette manière : une collectivité se dépouille et se fragilise dans la frénésie afin d'exciter la nature à compenser par une sorte de logique mimétique et de réciprocité magique. Il est loisible de retracer dans ce comportement des éléments du potlatch de la côte Ouest.

Cette attitude atavique explique en partie la surconsommation à laquelle cèdent les gens pendant le temps des Fêtes qui culmine aux jours gras ou à la 
Chandeleur comme c'est le cas en Acadie. À cette époque de l'année, pour cette portion d'Amérique, l'hiver amorce son déclin. Il a « le cou cassé ». Les provisions ont baissé, elles ont atteint le niveau critique " demi-cave, demi-grenier » (p. 21). Pour en évaluer la quantité, on remue la farine (p. 27). Dans les saloirs, la cuisinière a atteint le morceau de porc qui a conservé la queue, sorte de ligne de démarcation qui sépare l'hiver en deux. La marmotte ou la mouffette sort le bout de son nez. Si elle voit son ombre, en vertu de la loi des contraires, elle retourne à son hibernation. La saison froide peut prospérer encore pour six semaines. C'est dans ce contexte à la fois matériel et psychologique que s'inscrivent les célébrations de la Chandeleur.

«La journée des crêpes » forme le premier axe de la monographie et occupe la part congrue, ce qui n'enlève rien à son importance. D'après les témoignages compilés par Georges Arsenault, elle oscille entre une pratique familiale et élargie. La préparation et la consommation des crêpes donnaient lieu à de nombreuses pratiques propitiatoires, conjuratoires et divinatoires. Brûler ses crêpes faisait rouiller le blé sur pied. « [O]n ne mangeait jamais la dernière crêpe [...], c'était celle-là qui assurait la bonne récolte. On la mettait dans l'armoire et on la sauvait » (p. 27). Pour se prémunir du défaut d'argent, il suffisait « de coller la première crêpe de la Chandeleur dans le fond d'une armoire» (p. 28). Ceux qui ne sacrifiaient pas à cette coutume risquaient d'attraper des poux et la gale (p. 28). De plus, « il était important que chacun "vire" sa crêpe à la Chandeleur, c'est-à-dire la fasse sauter. Si on ratait la manœuvre et que la crêpe tombait par terre au lieu de retomber intacte dans la poêle, il fallait quand même la manger, parfois à même le plancher, ou bien s'en passer » (p. 28-29).

Certaines cuisinières dissimulaient divers objets emblématiques dans leurs crêpes dans le but de prédire l'avenir des gens. Un jonc signifiait le mariage, un bouton le célibat, une médaille la vie religieuse, un morceau de bois un charpentier ou un batteur de femmes, etc. (p. 32). Et, miracle d'économie domestique, il existait même une recette de crêpes à la neige pour pallier le manque d'œufs (p. 33).

Mais c'est la quête qui occupe, à juste titre, la majeure partie de la monographie. Courir la Chandeleur impliquait toute la société. Les « coureux » - généralement des jeunes hommes déguisés ou non - partaient en traîneaux, sous la conduite d'un chef qui se distinguait par son habillement plus relevé et une canne surmontée d'un coq (Île-du-Prince-Édouard) ou d'un cerceau (Nouvelle-Écosse), recueillir de la nourriture de porte en porte, ce qui rappelle la quête de l'Enfant Jésus.

Après s'être assurée du consentement des personnes visitées, la troupe entrait, prenait possession de la cuisine, exécutait danses et chansons, recueillait la nourriture et partait en entonnant un couplet de remerciement. Les 
denrées se composaient généralement de farine, de sucre, de lard, de viande de porc. La joyeuse bande apportait ces aliments à des ménagères réunies dans une vaste demeure afin qu'elles préparent un repas copieux où étaient conviés collecteurs, donateurs et leurs familles. Les surplus étaient distribués à une famille dans la misère. Cet appoint lui permettait de se rendre jusqu'au printemps sans périr de faim. D'une certaine manière, la quête de la Chandeleur et le banquet qui s'ensuivait étaient l'occasion, pour une collectivité, de s'offrir à elle-même des réjouissances qui nécessitaient l'implication de tous les acteurs de la fête. Avec cette activité au caractère hautement social, nous sommes en présence d'une société de participation et non de représentation comme c'est le cas aujourd'hui où ces festivités tendent à disparaître ou sont disparues.

Cette période d'exubérance que le carême viendra bientôt assagir n'était vraiment possible que si les membres de la collectivité, surtout les hommes, subissaient le désœuvrement du temps mort de l'hiver qui les débauchait jusqu'au retour de la belle saison. Dans une civilisation urbanisée qui nie le cycle des saisons, ce temps mort est inexistant.

Si la Chandeleur, aux dires de l'auteur, a donné des chansons aussi nombreuses que le cycle du temps des Fêtes ainsi que de nombreux dictons météorologiques, elle ne semble pas avoir été prodigue en légendes et en contes. Georges Arsenault ne s'attarde pas sur cette particularité, malgré le fait que l'absence d'un phénomène attendu soit aussi significative, sinon plus, que sa présence. Tout au plus glisse-t-il en passant deux récits légendaires qui sanctionnent ceux qui ne respectent pas la tradition des crêpes.

La Chandeleur en Acadie est le résultat d'une recherche exhaustive sur le terrain qui se tient loin de toute spéculation anthropologique. L'auteur suit l'évolution de cette coutume, en trace brièvement l'origine et compile les variations. Son objectif est de fournir des matériaux crédibles à des chercheurs plus orientés vers les grandes synthèses que préoccupés par la collecte des faits. Dans un style sobre, clair et accessible, ce qui dénote une certaine humilité devant son sujet et mérite d'être souligné, Georges Arsenault a accompli un travail essentiel de conservation et de diffusion.

Bertrand Bergeron

Saint-Bruno en Lac-Saint-Jean

Auzas, Vincent et Van Troi Tran [dir.]. Patrimoines sensibles : mots, espaces, pratiques. Québec, Les Presses de l'Université Laval, « Patrimoine en mouvement », 2010, 268 p. ISBN 978-2-7637-9040-4.

Les auteurs que Vincent Auzas et Van Troi Tran ont convoqués dans cet 